\title{
The Role of Brønsted and Lewis Acidity in the Green Synthesis of Homopropargyl Alcohols over HZSM-5
}

\author{
Balaga Viswanadham ${ }^{(\mathbb{D})}$, Sooboo Singh, Holger B. Friedrich and Abdul S. Mahomed ${ }^{*}$ (D) \\ Catalysis Research Group, School of Chemistry and Physics, University of KwaZulu-Natal, Durban, 4000, South Africa.
}

Received 10 July 2017, revised 23 March 2018, accepted 19 April 2018.

\begin{abstract}
A highly efficient and simple reaction under exceptionally mild conditions is shown for the synthesis of biologically and pharmaceutically active molecules of homopropargyl alcohol using HZSM-5 as the catalyst. Products analyzed by IR, 1H NMR, 13C NMR and GC-MS showed consistent yields of $98 \%$ of the alcohol, even with respective recycles of the regenerated catalyst. The reaction was also carried out with selected mineral acids, acidic oxides and other acidic catalysts to compare reactivity and the influence of the type of acidity involved in the reaction. The results indicate that the presence of both Brønsted and Lewis acidity is beneficial for inducing a high rate of reaction when compared to systems having either predominantly Brønsted or Lewis acidity.
\end{abstract}

KEYWORDS

Homopropargyl, zeolites, HZSM-5.

\section{Introduction}

Selective nucleophilic alkynylation of an epoxide in the synthesis of homopropargyl alcohol (HPA) is an important reaction in the transformation of organic compounds. HPAs are versatile building blocks for use in organic synthesis, especially for the synthesis of complex polyketide and macrolide structures, while its derivatives are useful in biological activity studies. ${ }^{1-6}$ HPA synthesis has been reported by the reactions of propargyl or allenyl organometallic derivatives of different metals..$^{78}$ The study undertaken by Lee et al., ${ }^{9}$ involving the reaction of propargyl bromide with benzaldehyde under sonochemical Barbier-type reaction conditions, produced HPA in a yield of $56 \%$. Recently, HPA synthesis has been reported by using propargyl boronates or allenylboronates with carbonyl compounds as reactants. ${ }^{10-11}$ The disadvantage of producing HPA through these synthetic routes is the difficulty in separating the catalyst from the products. Also, HPA synthesis requires the use of organic solvents, consequentially, this necessitates the use of extraction and chromatographic procedures to isolate and purify the product. Some methods also require heating of the reaction. ${ }^{6}$ The development of green chemical processes for the synthesis of HPA and other bio-active molecules based on atom economy or efficiency is gaining momentum at present. ${ }^{12-14}$ Solid acid catalysts seem most suitable for this type of work. ${ }^{15-19}$ Among these solid acid catalyst systems, zeolites exhibit superior catalytic performance in epoxide ring opening. ${ }^{20}$ Epoxides are important and well-known carbon electrophiles that can be industrially produced from the corresponding olefins. ${ }^{21}$ In this study, we report a facile and clean procedure for the synthesis of HPA using HZSM-5 in a solvent-free system. The method involves simple stirring of stoichiometric amounts of the respective epoxide and phenyl acetylene with HZSM-5 as the catalyst to produce a pure addition product. Further to this, a comparison of the activity was made with conventional mineral acids and acid type solids to establish the role of the relevant acid type, either Brønsted or Lewis, in establishing the reaction pathway.

* To whom correspondence should be addressed. E-mail: mahomeda1 @ukzn.ac.za

\section{Experimental}

\subsection{Materials}

The mineral acids, $\mathrm{HCl}, \mathrm{H}_{2} \mathrm{SO}_{4}, \mathrm{HNO}_{3}$ and $\mathrm{H}_{3} \mathrm{PO}_{4}$ were obtained from Associated Chemical Enterprises (SA); styrene oxide, cyclohexene oxide, phenyl acetylene, Amberlyst 15, were obtained from Sigma Aldrich and the oxides $\mathrm{SiO}_{2}, \mathrm{Al}_{2} \mathrm{O}_{3}, \mathrm{ZrO}_{2}$ and $\mathrm{TiO}_{2}$ were supplied by Alfa Aesar Ltd. HZSM-5 and NaZSM-5 were obtained from SC Zeolites Ltd. The oxides, HZSM-5 and NaZSM- 5 were calcined at $500{ }^{\circ} \mathrm{C}$ for $4 \mathrm{~h}$ prior to their use in the reaction.

\subsection{Catalyst Characterization}

Powder X-ray diffraction (XRD) studies were conducted on a Bruker D8 Advance instrument, equipped with an XRK 900 reaction chamber and a $\mathrm{Cu}$ radiation source with a wavelength of $1.5406 \AA$. Temperature-programmed desorption (TPD) of ammonia was done on a Micromeritics 2920 Auto Chem II Chemisorption instrument. For TPD experiments, the catalyst was pre-treated by passing through high purity helium $\left(30 \mathrm{~mL} \mathrm{~min}^{-1}\right)$ at $150{ }^{\circ} \mathrm{C}$ for $2 \mathrm{~h}$. After pre-treatment, the sample was saturated by passing $5 \% \mathrm{NH}_{3}$ in helium $\left(30 \mathrm{~mL} \mathrm{~min}^{-1}\right)$ at $80{ }^{\circ} \mathrm{C}$ for $1 \mathrm{~h}$. Finally, the catalyst was flushed with helium $\left(30 \mathrm{~mL} \mathrm{~min}^{-1}\right)$ at $150{ }^{\circ} \mathrm{C}$ for $1 \mathrm{~h}$ to remove the physisorbed ammonia. Thereafter, the sample was cooled to room temperature and analyzed from room temperature to $900{ }^{\circ} \mathrm{C}$ with a ramp rate of $10^{\circ} \mathrm{C}$ per min. Ex situ pyridine adsorbed FT-IR experiments were carried out to investigate the distribution of Brønsted and Lewis acid sites present on the catalyst. These experiments were carried out by adding about $20 \mathrm{mg}$ of pyridine on a small amount of the catalyst $(15 \mathrm{mg}$ ) followed by evacuation for $1 \mathrm{~h}$ (at room temperature) to remove the reversibly adsorbed pyridine. The spectra were then recorded on a Perkin-Elmer ATR spectrometer at room temperature. This was done in duplicate. The regeneration of the HZSM-5 was done by washing the used catalyst with dichloromethane to remove any organic matter, it was then dried at room temperature and thereafter calcined at $500{ }^{\circ} \mathrm{C}$ in air for $4 \mathrm{~h}$. 


\subsection{Catalytic Testing}

The epoxide $(10 \mathrm{mmol})$ together with phenyl acetylene (10 mmol) and $100 \mathrm{mg}$ of HZSM-5 were placed in a reaction flask and stirred continuously for $2-5 \mathrm{~min}$ at room temperature. The progress of the reaction to establish completion was monitored by TLC. The reaction mixture was then allowed to stand at room temperature for $5 \mathrm{~min}$ without stirring. Experiments were repeated, under the same conditions using the mineral inorganic acids as catalyst. The inorganic oxides were tested for $30 \mathrm{~min}$. In the case of the mineral acids, after the reaction was established to be complete, a small volume of brine solution was added to the reaction mixture, and thereafter the organic layer was separated and dried with anhydrous $\mathrm{Na}_{2} \mathrm{SO}_{4}$. The yields reported are the isolated yields after separation of the catalyst and the purity was determined by NMR spectroscopy. The replicate values are based on the number of experiments required to achieve a relative standard deviation of at least $1 \%$, usually $\mathrm{n}=3$. Where no reaction was observed for the time tested, the experiment was done in duplicate $(n=2)$.

\section{Results and Discussion}

\subsection{Catalyst Characterization}

X-ray diffractograms of fresh and regenerated HZSM-5 catalysts are shown in Fig. 1 . The regenerated catalyst refers to the catalyst that was subjected to recycle testing. Intense reflections at $2 \theta$ values of $8.2^{\circ}, 9.2^{\circ}, 14.2^{\circ}, 15.1^{\circ}, 16.2^{\circ}, 21.1^{\circ}, 23.4^{\circ}, 24.8^{\circ}$,

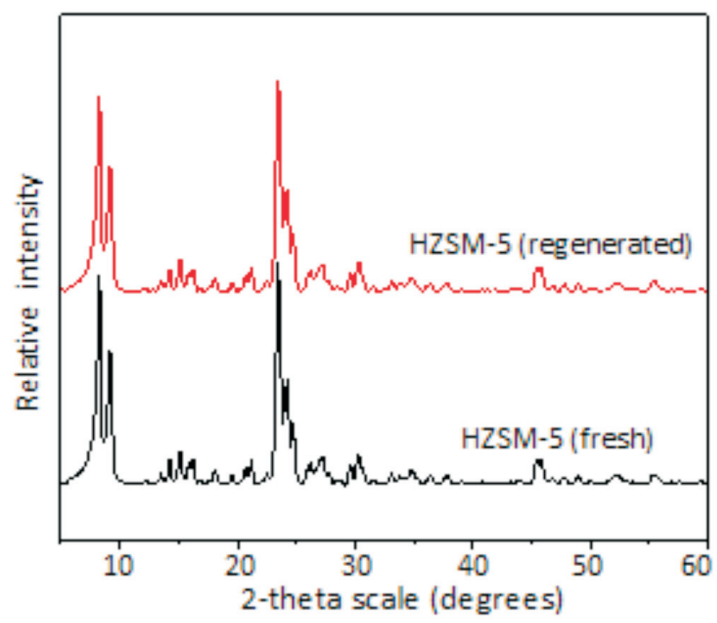

Figure 1 X-ray diffractograms of fresh and regenerated HZSM- 5 catalysts.

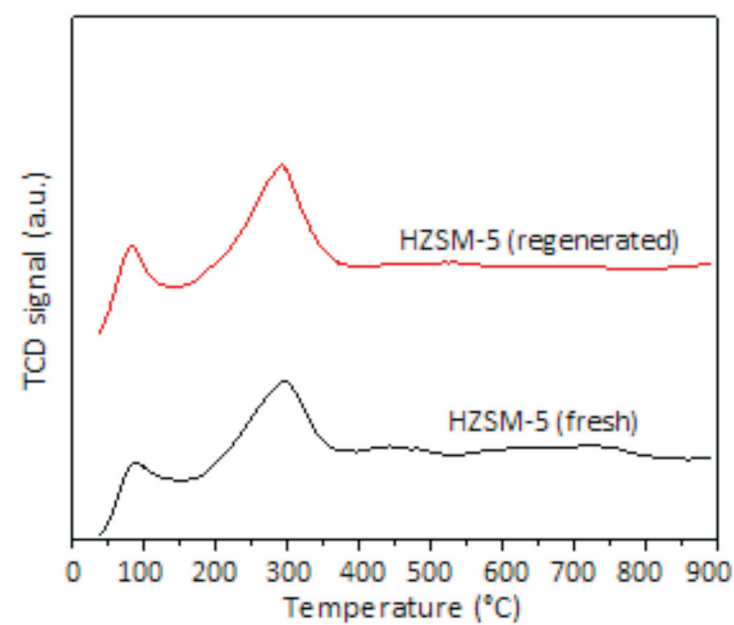

Figure $2 \mathrm{NH}_{3}$-TPD profile of fresh and regenerated HZSM- 5 catalysts. $26.2^{\circ}, 27.4^{\circ}, 29.6^{\circ}$ and $30.3^{\circ}$ correlate to reference peaks contained in JCPDS File No. 44-0002 for HZSM-5. Comparing the $X$-ray diffractograms of the fresh and used catalyst, very little change was noticed, suggesting excellent stability of the zeolite during recycle testing.

Temperature-programmed desorption (TPD) profiles of ammonia for the fresh and regenerated catalysts are shown in Fig. 2. From the TPD profiles, a desorption peak observed at about $300{ }^{\circ} \mathrm{C}$ was attributed to acidic sites having moderate strength, whereas a weak desorption peak at $100^{\circ} \mathrm{C}$ is due to the presence of weak acidic sites. A weak intensity peak is observed in the region between 700 and $800{ }^{\circ} \mathrm{C}$ and this is attributed to strong acidic sites. When compared to the fresh catalyst, the regenerated catalyst shows no significant changes, except in the case of strong acidic sites which are absent in the latter.

The nature of acidic sites such as Brønsted and Lewis, studied by ex situ pyridine FT-IR spectroscopy, of the fresh and regenerated catalysts are presented in Fig. 3. The vibration band appearing at $1580 \mathrm{~cm}^{-1}$ is assigned to Brønsted (B) acid sites, whereas the vibration band at $1438 \mathrm{~cm}^{-1}$ is attributed exclusively to Lewis (L) acid sites. The band observed at $1482 \mathrm{~cm}^{-1}$ is due to both Brønsted and Lewis $(B+L)$ acidic sites. From the IR results, there is very little variation in the acidity of the fresh and regenerated catalysts. These results correlate well with the $\mathrm{NH}_{3}$ TPD results. The ex situ pyridine FT-IR spectra of the inorganic oxides, $\mathrm{ZrO}_{2}, \mathrm{TiO}_{2}$ and $\mathrm{Al}_{2} \mathrm{O}_{3}$ are shown in Fig. 4. Lewis acidity appears most prominent for these oxides.

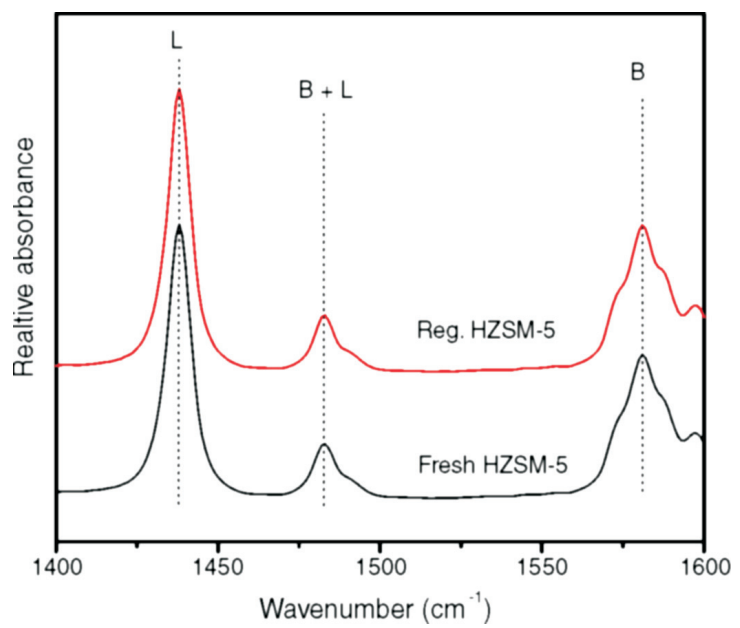

Figure 3 Pyridine adsorbed FT-IR spectra of the fresh and regenerated HZSM-5 catalysts.

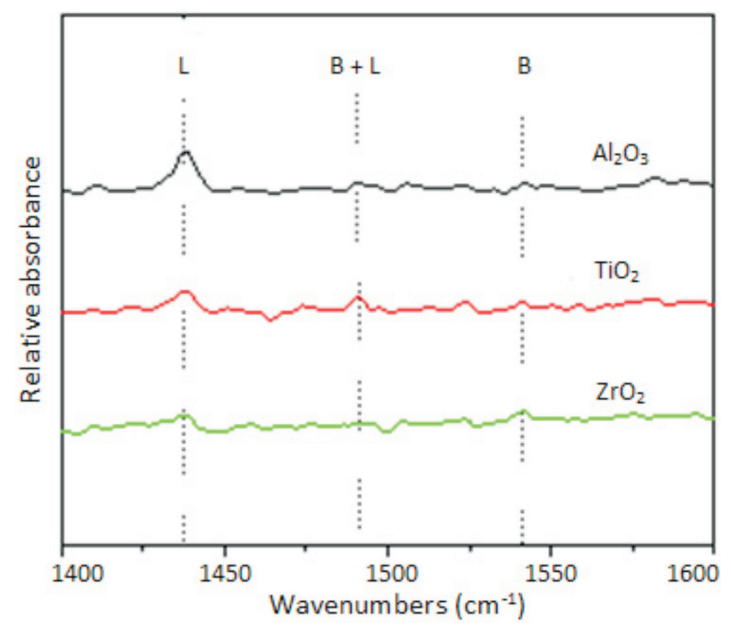

Figure 4 Pyridine adsorbed FT-IR spectra of $\mathrm{ZrO}_{2}, \mathrm{TiO}_{2}$ and $\mathrm{Al}_{2} \mathrm{O}_{3}$. 
On the other hand, Mordenite-40 and silylated HZSM-5, exhibited varying degrees of Brønsted and Lewis acidity as shown in Fig. 5. HZSM-5 is included in the figure for comparative purposes. The results reveal HZSM-5 as having a higher relative amount of Brønsted and Lewis acidity, by examination of the peak intensities, compared to the other systems. Silylated HZSM- 5 shows a significant decrease in Brønsted acidity and to some extent, the Lewis acidity as well.

\subsection{Catalytic Activity Studies}

Initially the catalytic effect of the inorganic mineral acids $\mathrm{HCl}$, $\mathrm{H}_{2} \mathrm{SO}_{4}, \mathrm{HNO}_{3}$, and $\mathrm{H}_{3} \mathrm{PO}_{4}$ was studied with both epoxides and phenyl acetylene (Schemes 1 \& 2). They all showed complete conversion of the epoxide (Tables 1 \& 2); however, the separation of the catalyst from the reaction mixture was difficult, which is reflected in the poor yields obtained. Thereafter, the synthesis of HPA was attempted with the inorganic acidic oxides; zirconia, titania, alumina and silica; however, no conversion of the reactants was observed, irrespective of the epoxide used (Tables 1 \&
2), even after 30 min of reaction time. When HZSM- 5 was tested, it showed excellent activity and the highest yield towards HPA, even compared to the mineral acids. It is thought that the combination of Lewis and Brønsted acid sites present in HZSM-5 is suitable for this type of reaction and it is apparent that a predominance of Lewis acidity, as shown by the inorganic oxides, is not sufficient to drive the reaction. Additionally, we believe that even a small amount of Brønsted acidity with Lewis acidity being present, as may be found in $\mathrm{Al}_{2} \mathrm{O}_{3}$, is not enough to drive the reaction at a high rate.

\subsection{Comparative Study}

In order to understand the relative contributions of both Brønsted and Lewis acidity of HZSM-5, other catalysts were tested and compared. This included the sodium form of HZSM-5, Mordenite 40, Amberlyst 15 and silylated HZSM-5. Na-ZSM-5, having the same Si/Al ratio as HZSM-5, showed no activity, even after $30 \mathrm{~min}$. Considering that Na-ZSM-5 has predominantly Lewis sites, its inactivity clearly suggests that the

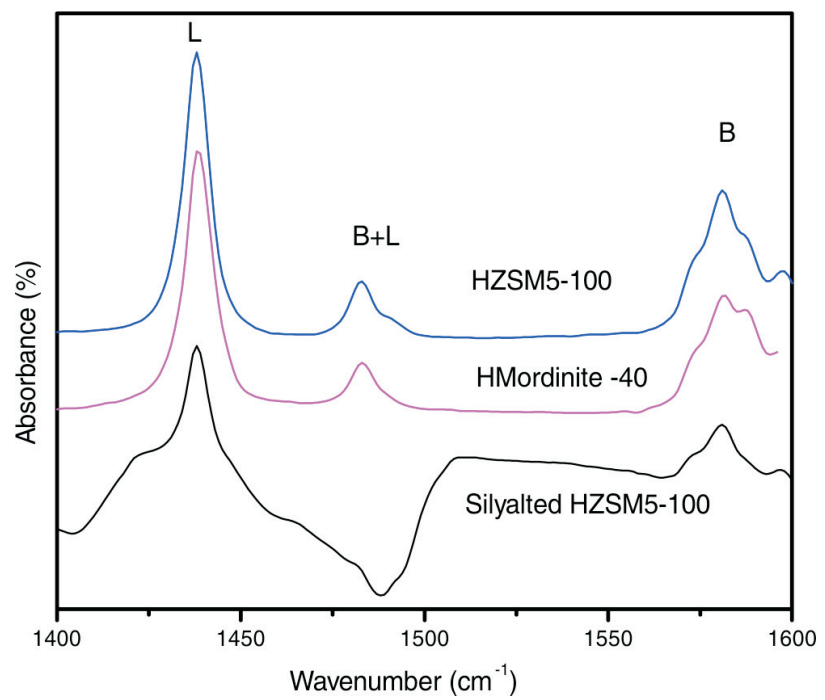

Figure 5 Pyridine adsorbed FT-IR spectra of HZSM- 5 and other materials.<smiles>C#Cc1ccccc1</smiles>

Scheme 1

Reaction between cyclohexene oxide and phenyl acetylene in presence of catalyst.<smiles>C#Cc1ccccc1</smiles>

Scheme 2

Reaction between styrene oxide and phenyl acetylene in presence of the catalyst. 
Table 1 Catalytic results of cyclohexene oxide with phenyl acetylene over the various catalysts.

\begin{tabular}{lccc}
\hline Catalyst & $\begin{array}{c}\text { Reaction }+\begin{array}{c}\text { Standing time } \\
\text { /min }\end{array} \\
\text { Conversion } \\
/ \%\end{array}$ & $\begin{array}{c}\text { Yield }^{\mathrm{a}} \\
/ \mathrm{mol}^{\%}\end{array}$ \\
\hline $\mathrm{Blank}$ & $30+0$ & - & $-^{\mathrm{b}}$ \\
$\mathrm{HCl}$ & $3+5$ & 100 & 88 \\
$\mathrm{H}_{2} \mathrm{SO}_{4}$ & $2+5$ & 100 & 85 \\
$\mathrm{HNO}_{3}$ & $2+5$ & 100 & 87 \\
$\mathrm{H}_{3} \mathrm{PO}_{4}$ & $1+5$ & 100 & 86 \\
$\mathrm{SiO}_{2}$ & $30+0$ & - & $-{ }^{\mathrm{b}}$ \\
$\mathrm{Al}_{2} \mathrm{O}_{3}$ & $30+0$ & - & $-{ }^{\mathrm{b}}$ \\
$\mathrm{ZrO}_{2}$ & $30+0$ & - & $-{ }^{\mathrm{b}}$ \\
$\mathrm{TiO}_{2}$ & $30+0$ & - & $-{ }^{\mathrm{b}}$ \\
$\mathrm{HZSM} 5$ & $4+5$ & 100 & 98 \\
\hline
\end{tabular}

a $100 \%$ selectivity towards addition product, $\mathrm{n}=3$ to achieve a RSD of no more than $1 \%$.

presence of Brønsted and Lewis acid sites is important for the reaction. To further test this assumption, we subjected the HZSM-5 to silylation and tested this for the HPA synthesis reaction. As can be observed from Table 3, this system also showed no activity, even after $30 \mathrm{~min}$ of reaction time. Considering that silylation occurs mainly on the external surface of the zeolite, the result may suggest that the high activity of HZSM- 5 may be due to the external surface only. We believe that the epoxide and phenyl acetylene are just slightly larger than the pores of the HZSM-5. The molecular sizes are given in the supplementary information (Table S1). However, it is also possible that the silylating agent may have, in addition to silylating the surface, reduced the size of the pore entrance as well, by bonding on the periphery. Thus, if the reaction did occur within the pores of the unmodified HZSM-5, the reduced size of the pore entrance negates that interaction after silylation. Amberlyst 15 was tested to establish how a strong Brønsted solid acid catalyst for epoxide ring opening with phenyl acetylene, behaves. This result also is shown in Table 3. It can be seen from the results that Amberlyst 15 was also inactive after $30 \mathrm{~min}$ of the reaction proceeding at room temperature. This suggests that Brønsted acidity on its own will not drive this reaction at a reasonable rate when compared to a system that contains both Brønsted and Lewis sites, such as HZSM-5. When Mordenite 40 was tested, to further establish any link in the relationship between Lewis and Brønsted acidity, a similar observation was made as for HZSM-5. However, it was noted that the rate was much lower, since this catalyst required $30 \mathrm{~min}$ of reaction time to achieve a similar activity to HZSM-5.
Table 2 Catalytic results of styrene oxide with phenyl acetylene over the various catalysts.

\begin{tabular}{lccc}
\hline Catalyst & $\begin{array}{c}\text { Reaction }+ \text { Standing time } \\
\text { /min }\end{array}$ & $\begin{array}{c}\text { Conversion } \\
/ \%\end{array}$ & $\begin{array}{c}\text { Yield }^{\mathrm{a}} \\
/ \mathrm{mol}^{\%}\end{array}$ \\
\hline $\mathrm{Blank}$ & $30+0$ & - & $-^{\mathrm{b}}$ \\
$\mathrm{HCl}$ & $3+5$ & 100 & 88 \\
$\mathrm{H}_{2} \mathrm{SO}_{4}$ & $2+5$ & 100 & 89 \\
$\mathrm{HNO}_{3}$ & $2+5$ & 100 & 88 \\
$\mathrm{H}_{3} \mathrm{PO}_{4}$ & $1+5$ & 100 & 85 \\
$\mathrm{SiO}_{2}$ & $30+0$ & - & $--^{\mathrm{b}}$ \\
$\mathrm{Al}_{2} \mathrm{O}_{3}$ & $30+0$ & - & $-{ }^{\mathrm{b}}$ \\
$\mathrm{ZrO}_{2}$ & $30+0$ & - & $-{ }^{\mathrm{b}}$ \\
$\mathrm{TiO}_{2}$ & $30+0$ & - & 98 \\
$\mathrm{HZSM} 5$ & $4+5$ & 100 & 98 \\
\hline
\end{tabular}

a $100 \%$ selectivity towards addition product, $\mathrm{n}=3$ to achieve a RSD of no more than $1 \%$.

${ }^{\mathrm{b}} \mathrm{n}=2$

\subsection{Reaction Mechanism}

Taking these observations into account, in addition to what was observed for the acidic oxides, a mechanism is proposed which is presented in Scheme 3. The mechanism shows the interaction of the terminal alkyne with a Lewis acid site due to the higher electron density around the triple bond. This allows the alkyne to behave similar to a Lewis base. The second step involves the protonation of the epoxide by its interaction with a Brønsted acid site in close proximity to the Lewis site. This is followed by addition of the adducts to give HPA via nucleophilic attack of phenyl acetylene at the sterically hindered carbon of the epoxide, and in the process, regenerating the catalytically active acid sites.

\subsection{Regeneration Studies}

The recovered HZSM-5 catalyst was characterized by XRD, ammonia TPD and pyridine adsorbed FT-IR spectroscopy to obtain information about the structural changes of the catalyst after the reaction. Before catalytic testing, and for preparation for the next cycle, the regenerated catalyst was activated by a simple oxidative treatment in air at $500{ }^{\circ} \mathrm{C}$ for $5 \mathrm{~h}$ to remove any organic residue. The XRD profiles of the regenerated catalysts show that the characteristic peaks were similar to those of fresh HZSM-5 (see Fig. 1). These XRD findings suggest that no significant structural changes occurred during the regeneration cycles. The results of temperature programmed desorption of ammonia for the fresh and regenerated catalysts are shown in Fig. 2. The ammonia TPD profiles reveal no significant change in total acidity of the fresh and regenerated catalyst. The results of $e x$ situ

Table 3 Comparison of catalytic results of HZSM- 5 over other solid acid catalysts.

\begin{tabular}{|c|c|c|c|c|}
\hline Catalyst & $\underset{\text { Reaction }+ \text { Standing time }}{\text { /min }}$ & Product & $\begin{array}{l}\text { Conversion } \\
\quad / \%\end{array}$ & $\begin{array}{l}\text { Yield }^{\mathrm{a}} \\
/ \mathrm{mol} \%\end{array}$ \\
\hline HZSM-5 & $4+5$ & & 100 & 98 \\
\hline NaZSM-5 & $30+0$ & & - & $-{ }^{\mathrm{b}}$ \\
\hline Amberlyst 15 & $30+0$ & & - & $-{ }^{\mathrm{b}}$ \\
\hline Silylated HZSM-5 & $30+0$ & & - & $-{ }^{b}$ \\
\hline H-Mordenite & $30+0$ & & 100 & 97 \\
\hline HZSM-5 & $4+5$ & & 100 & 98 \\
\hline NaZSM-5 & $30+0$ & & - & $-{ }^{b}$ \\
\hline Amberlyst 15 & $30+0$ & & - & $-{ }^{b}$ \\
\hline Silylated HZSM-5 & $30+0$ & & - & $-{ }^{\mathrm{b}}$ \\
\hline H-Mordenite & $30+0$ & & 100 & 96 \\
\hline
\end{tabular}

\footnotetext{
a $100 \%$ selectivity towards addition product, $\mathrm{n}=3$ to achieve a RSD of no more than $1 \%$.

${ }^{\mathrm{b}} \mathrm{n}=2$.
} 

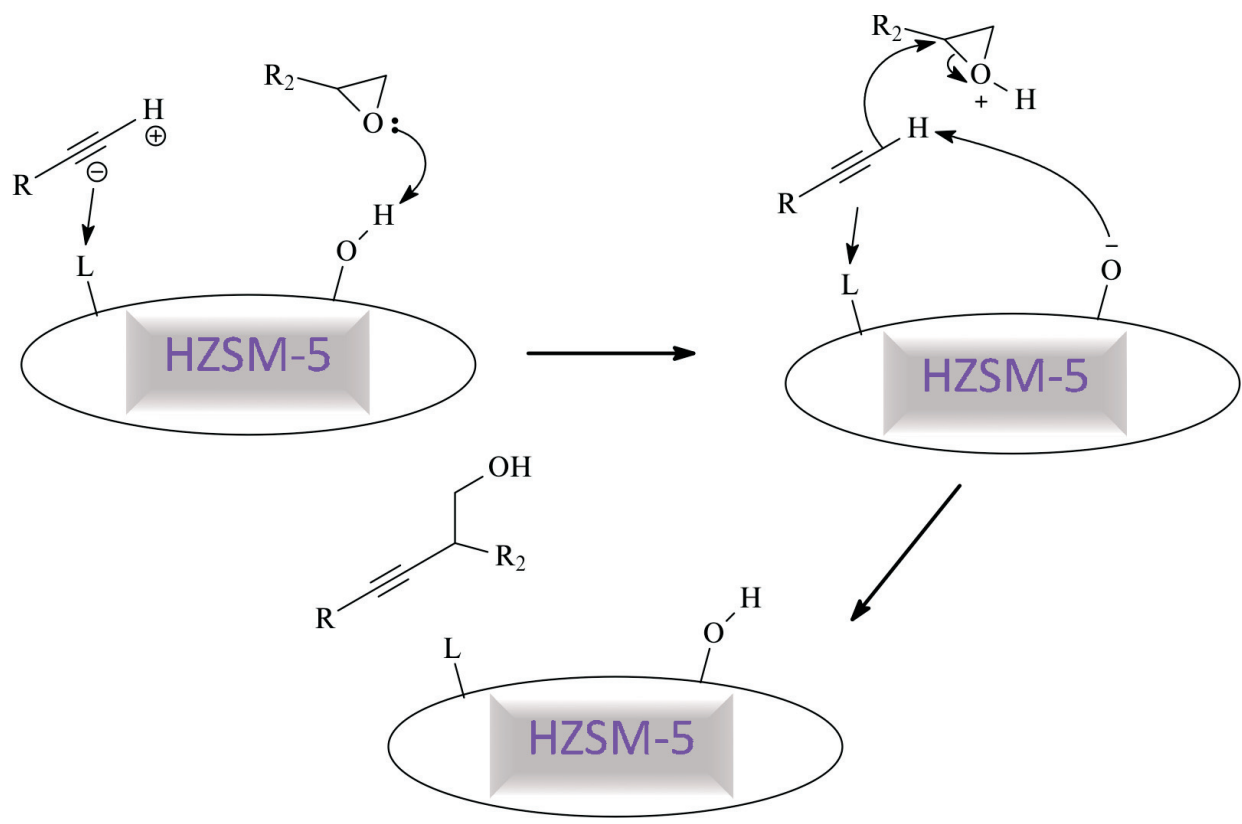

Scheme 3

Proposed reaction pathway of selective nucleophilic alkynylation of an epoxide over Brønsted \& Lewis acid sites.

pyridine adsorbed species of fresh and regenerated catalysts, as shown in Fig. 3, again reveal no significant change, based on the nature of the acid site distribution. A comparison of catalytic performance for the fresh and regenerated HZSM-5 catalyst is given in Table 4 . After five regeneration cycles, the regenerated HZSM-5 catalyst exhibited similar catalytic performance as the fresh catalyst.

\section{Conclusions}

In the present investigation, we have established a cleaner, safer, faster and environmentally sustainable approach by carrying out epoxide alkynylation reactions under exceptionally mild reaction conditions, such as ambient temperature and pressure, solvent-free, and with low amounts of catalyst. An excellent catalytic performance was exhibited by HZSM-5 for the synthesis of homopropargyl alcohols (HPA) compared to inorganic acids and some inorganic oxides. This produces a high purity product in excellent yield. With this new methodology, a number of homopropargyl alcohol derivatives can be synthesized under the principle of 'novel green technologies' by elimi- nating the use of highly volatile and hazardous conventional organic solvents and purification steps such as column chromatography or crystallization. Regenerated catalysts used over five recycles exhibited almost identical catalytic performance when compared to the fresh HZSM-5 catalyst. Mechanistically, we propose that the reaction of an epoxide with a terminal alkyne to produce HPA, occurs more readily with systems having both Brønsted and Lewis sites, whilst materials having predominantly either one or the other, shows no activity for the desired reaction under the conditions studied.

\section{Acknowledgements}

B.V. thanks the University of KwaZulu-Natal, Durban, South Africa, for the award of a Postdoctoral Fellowship. We also thank Süd-Chemie (now Clariant) for a donation of zeolite materials.

\section{${ }^{s}$ ORCID iDs}

B. Viswanadham: (iD orcid.org/0000-0002-1255-5500

A.S. Mahomed: ID orcid.org/0000-0002-5207-5384

Table 4 Conversion/yield over fresh and regenerated HZSM-5 catalysts.

\begin{tabular}{|c|c|c|c|c|c|}
\hline $\begin{array}{l}\text { Number of } \\
\text { recycles }\end{array}$ & $\begin{array}{l}\text { Total } \mathrm{NH}_{3} \text { uptake } \\
\qquad / \mathrm{cm}^{3} \mathrm{~g}^{-1}\end{array}$ & Reactant & Product & $\begin{array}{c}\text { Conversion } \\
1 \%\end{array}$ & $\begin{array}{l}\text { Yield }^{\mathrm{a}} \\
/ \mathrm{mol} \%)\end{array}$ \\
\hline Fresh & 12.10 & o & & 100 & 98 \\
\hline 1 st & 12.05 & & & 100 & 98 \\
\hline 2nd & 12.01 & & & 100 & 98 \\
\hline $3 r d$ & 11.98 & & & 100 & 98 \\
\hline 4th & 11.97 & & & 100 & 98 \\
\hline 5 th & 11.96 & & & 100 & 98 \\
\hline Fresh & 12.10 & & & 100 & 98 \\
\hline 1st & 12.05 & & & 100 & 98 \\
\hline 2nd & 12.01 & & & 100 & 98 \\
\hline $3 r d$ & 11.98 & & & 100 & 98 \\
\hline 4 th & 11.97 & & & 100 & 98 \\
\hline 5 th & 11.96 & & & 100 & 98 \\
\hline
\end{tabular}

a $100 \%$ selectivity towards addition product.

Experiment done in duplicate, RSD was less than $1 \%$. 


\section{References}

1 P. Gao, H. X. Li, X.H. Hao, D.P. Jin, D. O. Chen, X.B. Yan, X.X. Wu, X.R. Song, X.Y. Liu and Y.M. Liang, Facile synthesis of disubstituted isoxazoles from homopropargylic alcohol via C-N bond formation, Org. Lett., 2014, 16, 6298-6301.

2 S. Li and S. Ma, Highly Selective nickel-catalyzed methyl-carboxylation of homopropargylic alcohols for $\alpha$-alkylidene- $\gamma$-butyrolactones, Org. Lett., 2011, 13, 6046-6049.

3 C. Shu, M.Q. Liu, Y.Z. Sun and L.W. Ye, Efficient Synthesis of $\gamma$-lactones via gold-catalyzed tandem cycloisomerization/oxidation, Org. Lett., 2012, 14, 4958-4961.

4 K.C. Nicolaou, G. Skokotas, S. Furuya, H. Suemune and D.C. Nicolaou, Golfomycin A, a novel designed molecule with DNAcleaving properties and antitumor activity, Angew. Chem. Int. Edn., 1990, 29, 1064-1067.

5 A. Yanagisawa, S. Habaue and H. Yamamoto, Propargyl and allyl Grignard and zinc reagents. Regioselective alkylation and its application to the synthesis of PGE3 and F3.alpha. methyl ester, J. Org. Chem., 1989, 54, 5198-5200.

6 J. Tummatorn and G.B. Dudley, Ring opening/fragmentation of dihydropyrones for the synthesis of homopropargyl alcohols, J. Am. Chem. Soc., 2008, 130, 5050-5051.

7 M. Hojo, R. Sakuragi, S. Okabe and A. Hosomi, Allyl- and propargylchromium reagents generated by a chromium(III) ate-type reagent as a reductant and their reactions with electrophiles, Chem. Comm. 2001, 357-358.

8 T. Nakagawa, A. Kasatkin, F. Sato, Highly efficient synthesis of propargyl- and allenyltitanium reagents from propargyl halides or propargyl alcohol derivatives. Practical synthesis of allenyl and homopropargyl alcohols, Tetrahedron Lett., 1995, 36, 3207-3210.

9 A.S.Y. Lee, S.F. Chu, Y.T. Chang and S.H. Wang, Synthesis of homopropargyl alcohols via sonochemical Barbier-type reaction, Tetrahedron Lett., 2004, 45, 1551-1553.

10 P. Gao, Y.W. Shen, R. Fang, X.H. Hao, Z.H. Qiu, F. Yang, X.B. Yan, Q. Wang, X.J. Gong, X.Y. Liu and Y. M. Liang, Copper-catalyzed one- pot trifluoromethylation/aryl migration/carbonyl formation with homopropargylic alcohols, Angew. Chem. Int. Edn., 2014, 53, 76297633.

11 M. Chen and W.R. Roush, Enantioselective synthesis of anti- and syn-homopropargyl alcohols via chiral Brønsted acid catalyzed asymmetric allenylboration reactions, J. Am. Chem. Soc., 2012, 134, 10947-10952.

12 P.T. Anastas and J.C. Warner, Green Chemistry: Theory and Practice, ed., Oxford University Press, Oxford, 1998.

13 R.A. Sheldon, E factors, green chemistry and catalysis: an odyssey, Chem. Commun., 2008, 3352-3365.

14 R.A. Sheldon, Fundamentals of green chemistry: efficiency in reaction design, Chem. Soc. Rev., 2012, 41, 1437-1451.

15 A. Primo, and H. Garcia, Zeolites as catalysts in oil refining, Chem. Soc. Rev., 2014, 43, 7548-7561.

16 D.S. Barnett and S.E. Schaus, Asymmetric propargylation of ketones using allenylboronates catalyzed by chiral biphenols, Org. Lett., 2011, 13, 4020-4023.

17 D.R. Fandrick, K.R. Fandrick , J.T. Reeves , Z. Tan , C.S. Johnson, H. Lee, J.J. Song, N.K. Yee and C.H. Senanayake, Zinc catalyzed and mediated propargylations with propargyl boronates, Org. Lett., 2010, 12, 88-91.

18 L.R. Reddy, Chiral Brønsted acid catalyzed enantioselective propargylation of aldehydes with allenylboronate, Org. Lett., 2012, 14, 1142-1145.

19 T. Hirashita, Y. Suzuki, H. Tsuji, Y. Sato, K. Naito and S. Araki, Nickel-catalyzed indium(I)-mediated syn-selective propargylation of aldehydes, Eur. J. Org. Chem., 2012, 29, 5668-5672.

20 B. Tang, W. Dai, G. Wu, N. Guan, L. Li and M. Hunger, Improved postsynthesis strategy to Sn-beta zeolites as Lewis acid catalysts for the ring-opening hydration of epoxides, ACS Catal., 2014, 4, 28012810.

21 J.H. Huang, T. Akita, J. Faye, T. Fujitani, T. Takei and M, Haruta. Propene epoxidation with dioxygen catalyzed by gold clusters, Angew. Chem., Int. Edn., 2009, 48, 7862-7866. 


\section{Supplementary material to:}

B. Viswanadham, S. Singh, H.B. Friedrich and A.S. Mahomed,

The Role of Brønsted and Lewis Acidity in the Green Synthesis of Homopropargyl Alcohols over HZSM-5

S. Afr. J. Chem., 2018, 71, 62-67. 
The Role of Brønsted and Lewis Acidity in the Green Synthesis of Homopropargyl Alcohols over HZSM-5

Balaga Viswanadham, ${ }^{\text {a }}$ Sooboo Singh, ${ }^{a}$ Holger B. Friedrich, ${ }^{a}$ and Abdul S. Mahomed ${ }^{* a}$

a Catalysis Research Group, School of Chemistry and Physics, University of KwaZulu-Natal, Durban South Africa 4000 .

* To whom correspondence should be addressed, Email: mahomeda1@ukzn.ac.za

\section{Supplementary Information}

Table S1 Molecular sizes of reactants

\begin{tabular}{|c|c|}
\hline Compound & Molecular size $(\AA)$ \\
\hline Styrene oxide & $7.29 \times(5.5$ to 6$)$ \\
\hline Phenyl acetylene & $7.7 \times(5.5$ to 6$)$ \\
\hline Cyclohexene oxide & $4.92 \times(5.5$ to 6$)$ \\
\hline
\end{tabular}

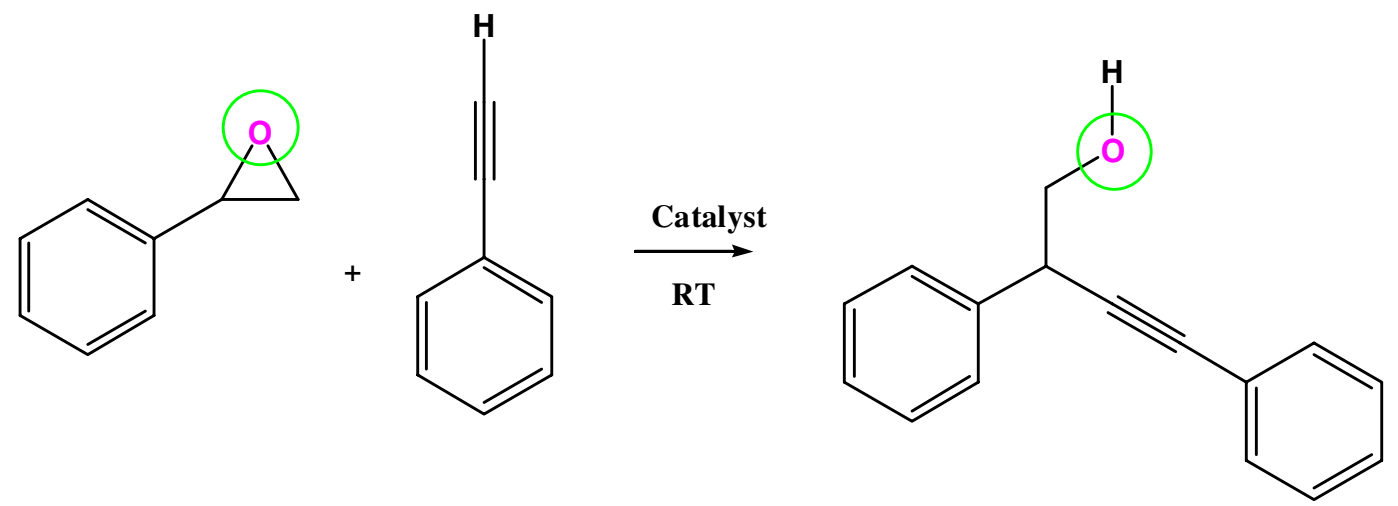

Styrene oxide + phenyl acetylene 


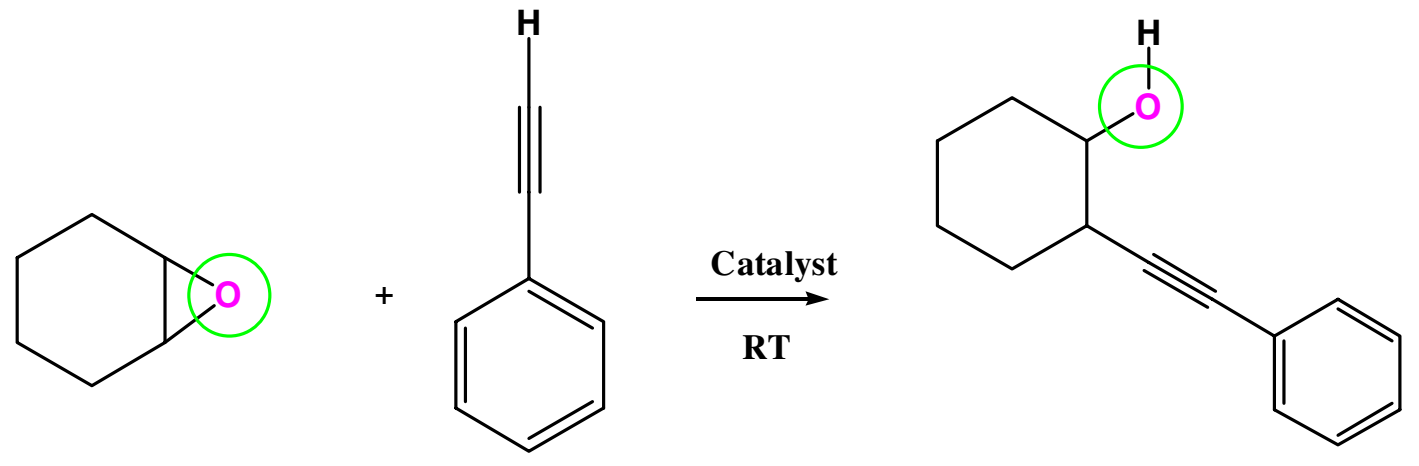

Cyclohexene oxide + phenyl acetylene 